\title{
Bioaerosols during transanal minimally invasive surgery
}

\author{
Jeffrey Dalli ${ }^{1}$ - Niall Hardy ${ }^{1}$ - M. Faraz Khan ${ }^{1,2} \cdot$ Ronan A. Cahill ${ }^{1,2}$
}

Accepted: 5 November 2020 / Published online: 13 November 2020

(C) Springer-Verlag GmbH Germany, part of Springer Nature 2020

\begin{abstract}
Background There is concern regarding bioaerosols from patients having procedures impacting surgical team safety. As pathogens and pollutants have been found in surgical smoke, we examined the potential for aerosol escape during transanal minimally invasive surgery (TAMIS) which may be particularly important given the presence of faecal contamination in the operative workspace and the specifics of its access platforms.

Methods Both qualitative (thermographic imaging) and quantificative (particle counting) methods were used to assess for aerosol release during TAMIS in comparison to laparoscopic operations of similar duration and equipment both at times of surgical dissection and without. TAMIS was performed using a Gelport Path Device (Applied Medical) and Airseal insufflation with valveless trocar (ConMed).

Results Significant carbon dioxide $\left(\mathrm{CO}_{2}\right)$ escapes during TAMIS carrying with it considerable numbers of particles. In general, particle counts were low prior to tissue dissection phases of the operation but increased substantially $\left(25 \times 10^{6} / \mathrm{m}^{3}\right.$ or over $40 \times$ background counts) during hook cautery dissection. The majority of particles were in the $0.3-0.5$ micron range (where counts were increased relative to background between $42 \times$ and 65 ) with the highest relative increase versus background in the $0.5-1.0$ micron range. Particle counts $<5$ were substantially greater during the TAMIS procedure versus laparoscopic procedures (a laparoscopic-assisted parastomal hernia repair and laparoscopic cholecystectomy) employing similar tools. Conclusions Considerable amounts of particle-rich aerosols escape during TAMIS procedures. Although pathogens are not proven to definitely spread to healthcare staff by such material nebulisation, N95/FFP2 masks, at a minimum, seem prudent while other methods evolve to eliminate this risk.
\end{abstract}

Keywords Aerosols $\cdot$ TAMIS $\cdot$ TATME $\cdot$ Surgical team safety $\cdot$ Surgical smoke

\section{Introduction}

The COVID-19 pandemic has spotlighted the hazard of operating room personnel contracting serious infection from patients during procedures [1]. The aerosolization risk at minimally invasive surgery has been an especial concern given that the gas used to distend intracorporeal cavities can leak unfiltered into the operating room carrying with it any pollutant and pathogenic particles from the internal operating workspace [2-4]. While the transmissibility of pathogens by such a route remains uncertain, chemical constituents of

Ronan A. Cahill

Ronan.cahill@ucd.ie

1 UCD Centre for Precision Surgery, University College Dublin, Dublin, Ireland

2 Department of Surgery, Mater Misericordiae University Hospital, Dublin, Ireland surgical smoke can cause respiratory irritability and some are known to be mutagenic [5].

Transanal minimally invasive surgery (TAMIS) enables deployment of laparoscopic instruments intrarectally to achieve precise rectal dissection. Most commonly, TAMIS and its derivative Transanal total mesorectal excision (taTME) use a specific access device (Gelpoint Path, Applied Medical, Rancho Santa Margarita, CA, USA). In addition, proponents advocate use of a high-powered insufflation system with access port (Airseal ${ }^{\mathbf{T M}}$, ConMed, Utica, USA) in order to maintain a stable operating field by minimising the fluctuations that otherwise occur due to gas leakage [6] and ensure efficient smoke evacuation [7]. While the Gelpoint Path platform is provided with valved access trocars, the Airseal system is often used with its valveless trocar. Both types of trocars allow gas to escape unfiltered $[3,8]$. In use during TAMIS/taTME, also, these access devices lie in a horizontal position, different to the more vertical position with laparoscopic use. This means that fluid (blood, 
faeces and fluid) can enter directly into the trocar channels risking considerably more contamination of the operating room airspace (especially that occupied by the surgeon and assistant who are positioned close to the access interface). We sought to evaluate if indeed this occurs.

\section{Methods}

With institutional approval and informed patients' and team consent (AEROSOLVE Study, IRB 1/378/2172), analytical measurements were carried out during TAMIS procedures using the Gelpoint Path access platform with two valved trocars in tandem with the Airseal insufflation system via its valveless access. Hook diathermy was used for cautery and at these times Airseal smoke evacuation mode was used. Carbon dioxide $\left(\mathrm{CO}_{2}\right)$ gas leakage via the access port was examined using a sensitive thermographic camera (FLIR 343, FLIR Systems Ltd, UK) to visualise gas escape. Secondly, a sensitive particle handheld counter (Model 8306, Particles Plus, Stoughton, MA, USA) was used after training to measure particle counts occurring intraoperatively in the local operating room for sampling periods of 30-s duration. The particle counter cumulatively measures particles by laser diode with differential counting between 0.3 and 25 microns at a flow rate of $0.1 \mathrm{CFM}(2.83 \mathrm{LPM})$ as well as humidity and temperature. Particle counts were measured at baseline (prior to operation) as well as intraprocedurally by placing the device's isokinetic probe inlet $10 \mathrm{~cm}$ from the region of interest at each time point. For comparison, additional readings were taken similarly during laparoscopic procedures also using an Airseal device. Procedures were performed within an operating room environment with positive pressure ventilation (PPV, 25 room air changes $/ \mathrm{hr}$ ) with room temperature settings between 18 and $20^{\circ} \mathrm{C}$ and humidity 50 $60 \%$. Hospital protocols regarding personal protective equipment and respect of the sterile field were adhered to at all times including, at this time, COVID-19 screening.

\section{Results}

Significant $\mathrm{CO}_{2}$ escape was thermographically visualised related to the transanal access port during use in TAMIS with a significant jetstream flowing continuously from the Airseal access trocar after commencement of gas insufflation (see Figure 1 and Video 1). Gas leak was also seen occurring episodically at other access points. The results of the particle count measurement are shown in Table 1. In general, particle counts were low prior to dissection phases of the operation but increased substantially $\left(25 \times 10^{6} / \mathrm{m}^{3}\right.$ or over $40 \times$ background counts) during tissue dissection with hook cautery. The majority of particles were in the $0.3-0.5$ micron range (where counts were increased relative to background between $42 \times$ and 65 ) with the highest relative increase versus background in the 0.5-1.0 micron range. High amounts of smallest size particles remained present at the time of specimen extraction despite desufflation of gas from the rectum via the Airseal
Fig. 1 Composite frames from thermographic video showing carbon dioxide jetstreams arising (a) continuously from the Airseal valveless access trocar (b) episodically from the valved trocars of the Gelpoint Path platform (c) intermittently from the insertion point of the Gelpoint Path device and (d) clouding in the operative airspace from all sources

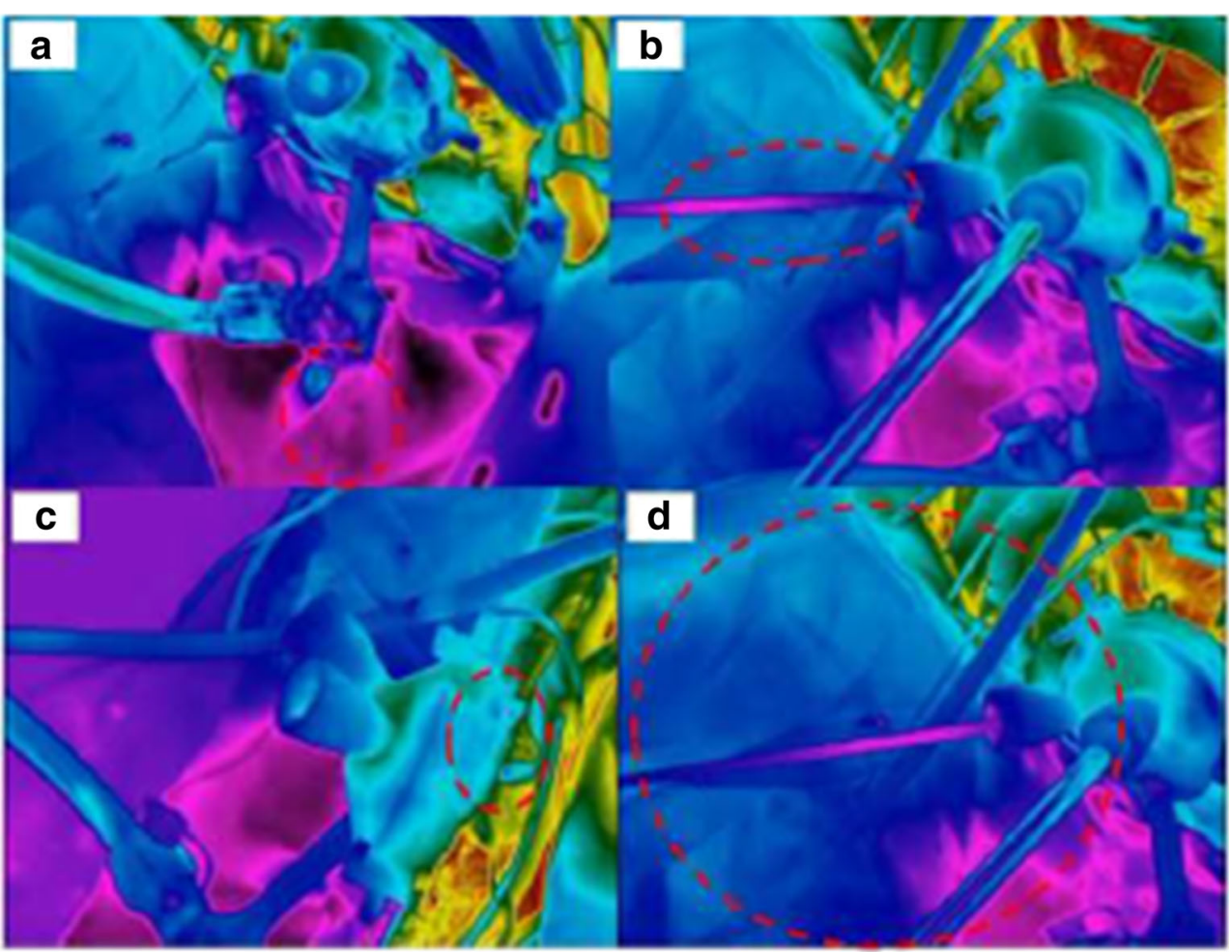


Table 1 Particles counts of local operative airspace external to the patient during TAMIS operation with counts from laparoscopic operations (also using Airseal for insufflation and hook diathermy for dissection) of similar duration. .bgd background. Colour shading in the table denotes increasing values within the individual columns per operation. For absolute readings green denotes least, orange middle and red highest. Re background ratios, white represents the lowest with shades of red darkening with higher values

\begin{tabular}{|c|c|c|c|c|c|c|c|c|c|c|c|c|c|c|}
\hline Procedure & Operative Phase & Total Particles & 0.3 & $0.3 / \mathrm{bgd}$ & 0.5 & $0.5 / \mathrm{bgd}$ & 1.0 & $1 /$ bgd & 2.5 & $2.5 / \mathrm{bgd}$ & 5 & $5 /$ bgd & 10 & $10 /$ bgd \\
\hline TAMIS & Background & 580218 & 370097 & 1 & 125367 & 1 & 39905 & 1 & 26133 & 1 & 8828 & 1 & 9888 & 1 \\
\hline \multirow{3}{*}{ High Evac Mode } & During Dissection & 25646213 & 17003304 & 46 & 6151108 & 49 & 1662614 & 42 & 629307 & 24 & 124307 & 14 & 75573 & 8 \\
\hline & Post Dissection (near Airseal) & 37145021 & 24589248 & 66 & 9112243 & 73 & 2497806 & 63 & 578807 & 22 & 187167 & 21 & 179751 & 18 \\
\hline & Post Dissection (near Gelpoint interface) & 33519265 & 24163000 & 65 & 7323555 & 58 & 1563027 & 39 & 300174 & 11 & 93230 & 11 & 76279 & 8 \\
\hline Low Evac Mode & Post Dissection & 6926262 & 5638692 & 15 & 1018474 & 8 & 171629 & 4 & 67451 & 3 & 16245 & 2 & 13772 & 1 \\
\hline Insufflation Off & Specimen Extraction & 3940406 & 3599976 & 10 & 238020 & 2 & 50146 & 1 & 31783 & 1 & 11300 & 1 & 9181 & 1 \\
\hline \multirow{3}{*}{$\begin{array}{l}\text { Laparoscopic-assisted } \\
\text { Parastomal Hernia Repair }\end{array}$} & Background & 126188 & 60505 & 1 & 33901 & 1 & 9888 & 1 & 14361 & 1 & 3295 & 1 & 4237 & 1 \\
\hline & During operation pre-Airseal & 120538 & 68510 & 1 & 36962 & 1 & 3766 & 0 & 5650 & 0 & 1883 & 1 & 3766 & 1 \\
\hline & During operation with Airseal & 362326 & 180105 & 3 & 123248 & 4 & 30723 & 3 & 18716 & 1 & 3884 & 1 & 5650 & 1 \\
\hline \multirow{4}{*}{$\begin{array}{l}\text { Laparoscopic } \\
\text { Cholecystectomy }\end{array}$} & Background & 55501 & 18363 & 1 & 19,069 & 1 & 6356 & 1 & 11300 & 1 & 261 & 1 & 152 & 1 \\
\hline & $\begin{array}{l}\text { With Airseal, predissection of gallbladder from } \\
\text { liver bed }\end{array}$ & 830672 & 629071 & 34 & 179869 & 9 & 5885 & 0 & 5650 & 0 & 6386 & 24 & 3811 & 25 \\
\hline & $\begin{array}{c}\text { With Airseal during dissection of gallbladder from } \\
\text { liver bed }\end{array}$ & 1973651 & 435782 & 24 & 21188 & 0 & 4237 & 0 & 8475 & 0 & 1466992 & 5620 & 36977 & 243 \\
\hline & With Airseal After Dissection from Liver bed & 44039 & 12713 & 0 & 8475 & 0 & 1412 & 0 & 3531 & 0 & 17763 & 68 & 146 & 0 \\
\hline
\end{tabular}

insufflation device. Particle counts $<5$ were substantially greater during the TAMIS procedure versus laparoscopic procedures (a laparoscopic-assisted parastomal hernia repair and laparoscopic cholecystectomy) employing similar tools (although notably increased particle counts were also be found in the operative airspace during the non-TAMIS procedures).

\section{Discussion}

When $\mathrm{CO} 2$ used to create space internally escapes to the exterior during TAMIS, considerable quantities of particles transfer with it even in the presence of smoke evacuation settings, as had been suggested possible by prior experimental work [9]. These particles include some of very small size (< 0.5 microns) which are important as such particles may remain airborne for a substantial period of time. While larger particles tend to fall to the ground, they first travel considerable distances in the turbulent jetstream before doing so. The small particle counts in aerosols at TAMIS are higher than for laparoscopic operations for similar timeframes perhaps because of the greater contamination of rectal fluid (including blood and enteric matter) directly into the access devices during operations. While the information for users sheet for the Airseal does recommend "positioning the patient lower than the device" for laparoscopy [10], it and its valveless trocar have been specifically approved for TAMIS use [11] even though this requires in-patient positioning. Although infection has not been proven to definitely spread to healthcare staff by such material nebulisation, chemical constituents of surgical smoke are known to be pathogenic. Therefore, N95/FFP2 masks, at a minimum, seem prudent [12] while other engineering methods evolve to ensure greater surgical team safety.

Supplementary Information The online version contains supplementary material available at https://doi.org/10.1007/s00384-020-03796-4.

Acknowledgments The authors gratefully acknowledge the expertise and training in particle counts by Mr Stephen Ryan, Spectrum Environmental, Dublin, Ireland.

\section{Compliance with ethical standards}

Disclosures RAC has received speaker fees from Stryker and Ethicon JnJ, consultancy fees from Touch Surgery and Distal Motion, research funding from Intuitive Surgery, from the Irish Government with IBM Research and Deciphex and from EU Horizon 2020 with Palliare Surgical. JD, MKK and NH have no conflicts of interest to declare.

\section{References}

1. Francis N, Dort J, Cho E, Feldman L, Keller D, Lim R, Mikami D, Phillips E, Spaniolas K, Tsuda S, Wasco K, Arulampalam T, Sheraz M, Morales S, Pietrabissa A, Asbun H, Pryor A (2020) SAGES and EAES recommendations for minimally invasive surgery during COVID-19 pandemic. Surg Endosc 34(6):2327-2331. https://doi.org/10.1007/s00464-020-07565-w 
2. Cahill RA, Dalli J, Khan M, Flood M, Nolan K (2020) Solving the problems of gas leakage at laparoscopy. Br J Surg 27. https://doi. org/10.1002/bjs.11977 Online ahead of print

3. Khan MF, Dalli J, Cahill RA (2020) Dynamic near-infrared carbon dioxide leak visualization detection during surgery using the FLIR GF343 optical imaging system. Surg Endosc In Press

4. Uecker JM, Fagerberg A, Ahmad N, Cohen A, Gilkey M, Alembeigi F, Idelson CR (2020) Stop the leak!: Mitigating potential exposure of aerosolized COVID-19 during laparoscopic surgery. Surg Endosc 24. https://doi.org/10.1007/s00464-020-08006-4

5. Limchantra IV, Fong Y, Melstrom KA (2019) Surgical smoke exposure in operating room personnel: a review. JAMA Surg 154(10): 960-967. https://doi.org/10.1001/jamasurg.2019.2515

6. Khan MF, Cahill RA (2020) Carbon dioxide gas leaks during transanal minimally invasive surgery. Tech Coloproctol 7:1-2. https://doi.org/10.1007/s10151-020-02284-9 Online ahead of print

7. Adamina M, Buchs NC, Penna M, Hompes R, on behalf of the St.Gallen Colorectal Consensus Expert Group (2018) St.Gallen consensus on safe implementation of transanal total mesorectal excision. Surg Endosc 32(3):1091-1103. Published online 2017 Dec 12. https://doi.org/10.1007/s00464-017-5990-2
8. Dalli J, Khan MF, Nolan K, Cahill RA (2020) Laparoscopic pneumoperitoneum escape and contamination during surgery using the airseal insufflation system: video vignette. Color Dis 9. https://doi. org/10.1111/codi.15255 Online ahead of print

9. Khan MF, Dalli J, Cahill RA (2020) Gas aerosol jetstreams from trocars during laparoscopic surgery - a video vignette. Color Dis 24. https://doi.org/10.1111/codi.15215 Online ahead of print

10. Surgiquest (2018) AirSeal iFS intelligent flow system instructions for use. In: MDSS GmbH

11. Samuel J. https://www.medindia.net/news/airseal-surgiquestsvalve-free-trocar-gets-fda-approval-for-transanal-endoscopy149626-1.htm Accessed 12/11/2020

12. Liu Y, Song Y, Hu X, Yan L, Zhu X (2019) Awareness of surgical smoke hazards and enhancement of surgical smoke prevention among the gynecologists. J Cancer 10(12):2788-2799. https://doi. org $/ 10.7150 /$ jca.31464

Publisher's note Springer Nature remains neutral with regard to jurisdictional claims in published maps and institutional affiliations. 